\title{
Poetry as Hybrid Pedagogy in Mental Health Nurse Education
}

\section{Nigel P. Short and Alec Grant}

\section{Introduction}

Poetry has emerged as a significant resource in nurse education in recent times. Over the last four years for example, this journal has hosted a number research and theoreticalconceptual papers that discuss and evaluate the use of poetry in undergraduate nurse curricula. In these papers, their authors express the explicit aim of advancing nurse education through helping students to explore their feelings about practice issues over a range of contexts. Included among these are reflective writing (Coleman and Willis, 2015), compassionate practice (Curtis, 2013), the development of emotional intelligence (Jack, 2015), the promotion of liberal nurse education (McKie, 2012) and clinical practice artistry (Chan, 2014), and the use of poetry to remove barriers to perception (Rolfe, 2012).

From a related but qualitatively different emerging contemporary perspective, our aim in this paper is to promote poetry as hybrid pedagogy in mental health nurse education. We do so in order to challenge longstanding epistemological assumptions guiding aspects of the conventional range, content and delivery of the mental health nursing curriculum. We wish to highlight the value of adding the poetic work in context, of academics who have hybrid, 'hyphenated' identities to this curriculum. In our case, this is reflected in the fact that we 
explicitly teach and write from the standpoint position of mental health/nurse lecturers-exmental health professionals-survivors of the UK psychiatric system (Grant et al., 2015a).

We will explore this topic area further and in a more nuanced way in this current paper. In specifically focusing on poetry as hybrid pedagogy, one of our own co-written and previously unpublished poems will be used in a theoretical and analytical context to advance our argument for the use of this approach in mental health nurse education. In the final section of our paper, our attention will turn to some of the benefits and one possible drawback for this approach, emerging from our discussion.

\section{Poetry as hybrid pedagogy}

As scholars with a background in healthcare, and nurse and mental health nurse education, we believe that poetry has great potential for developing pedagogic practice in undergraduate teaching. Like most of the colleagues we have worked with, we have throughout our academic careers generally conformed to an implicitly accepted norm of presenting new knowledge in prose narrative form. However, we are mindful of an argument that has been prescient for over two decades. This is that prose writing as an epistemological convention for conveying knowledge conceals an unexamined code regarding its sufficiency for how knowledge in general should or could be presented (Richardson, 1993).

This assumed sufficiency has not gone unchallenged. As a way of seeing through and beyond the knowledge conveyed in prose form, Richardson $(1993, \mathrm{p} 4)$ asserted that poetry touches 
readers in embodied rather than propositional or cognitive ways, implicitly inviting them to '...vicariously experience the self-reflexive and transformational process of self-creation...' Moreover, the poetic form of 'settling words together in new configurations lets us see, and feel the world in new dimensions.' (Richardson, 2000, p933). In this context, Richardson (2000) contends that in challenging conventional academic representational forms, poetic writing stimulates different kinds of analyses. Unpacking the potential meanings of poems, and the myriad allusions and references contained within them, can result in an expansion of knowledge about the people who wrote them and the circumstances and events described in them.

\section{Poetry in the Health Humanities paradigm}

In ways that complement Richardson's overall position, poetry, including that appearing in our previously published work (Grant, 2011; Short, 2011), has been acknowledged as having great significance as a pedagogic narrative resource in the context of the emerging Health Humanities paradigm (Crawford et al., 2015). In this context, reinforcing the benefits stated above and in the previous work mentioned at the outset of this paper, poetry can provide nursing students with powerful insights, increased levels of empathy, and wider frames of conceptual and experiential understanding.

In using poetry as a hybrid pedagogic tool, the emphasis moves away from the search for 'facts' and 'truth' to an activity geared more towards co-creating and co-constructing knowledge on the basis of either the presence of the hybrid teacher or, if this is not possible, their poetic work. As we will discuss in more detail below, as hybrid academics involved largely in prose writing for publication, we have found that creatively exploring the 
same issues through writing poetry helps us balance and develop our scholarship through casting new light on these issues. By extension, this in turn can only advance the already acknowledged valuable practice of reflection and reflexivity among nursing students. As a pedagogic approach, poetry therefore creates a space for writers and readers to explore events and ways of experiencing the world which are often silenced by conventional knowledge and curricular content.

The use of poetry as hybrid pedagogy also provides opportunities to develop a healthy scepticism towards the sufficiency of longstanding, dominant professional and institutional narratives for conceptualising and understanding mental health service users and their experiences. These narratives are always already predicated on a normatively accepted divide between professional nurse and service user. They often present as benign and helpful practices and assumptions which are frequently experienced by service users as oppressive (Grant et al., 2015a). The development of such scepticism can therefore enable nurse educators, hybrid or otherwise, and their students to use poetry to more readily acknowledge the legitimacy and relevance of lived experience as a focus for critical inquiry.

By providing space for aspects of hitherto unfamiliar worlds to become known, traditional knowledge practices can be thus be challenged and qualified. After Bakhtin (1984), the 'carnivalesque' possibilities of poetry can temporarily suspend often slavish adherence to hierarchal, traditional and dominant ways of knowing, in playful, interesting and imaginative ways. This has implications for personal development and future nursing practice in the context of recent radical shifts in understanding mental health difficulties and related professional practice. For example, poetry as hybrid pedagogy can help trouble students' 
often exclusive reliance on biomedical, binaried ways of conceptualising service users' problems in terms of rigid 'well-ill' categories (Grant, 2015). In turn, this can facilitate the emergence of a plurality of more fluid ways of understanding the identities of users of healthcare in terms of difference rather than pathology. This is discussed and reflected in both recent Queer paradigm work (Grant et al., 2015b), and in principles, practices and understandings emerging from the Psychosocial paradigm (Grant, 2015; Smith and Grant, 2016).

\section{Introduction to the poem}

We have argued above for the importance of poetry as hybrid pedagogy in challenging longstanding epistemological assumptions informing conventional practices in mental health nurse education. We have contextualised this argument in the emerging Health Humanities, Queer and Psychosocial paradigms. Our discussion will now turn to providing necessary preliminary information by way of introduction to our poem.

As established autoethnographic scholars (Short et al., 2013), we are well-attuned to the power of poetic representations for conveying lived experiences in rich and deep ways. Moreover, we both share an interest in contemporary and classical poetry, in the range of main poetic structures, and in the power of poetry in its autobiographical narrative form to positively contribute to the formation of human identity (Cobley, 2014). We hold to the idea that reflexive identity development can be best achieved by using narrative practices to work towards increasing health and wellbeing in broad existential, rather than solely in narrow, biomedical terms (Crawford et al 2015). We have also previously used our own poetry in our sustained narrative inquiry work in mental health survival and recovery (Grant, 
2010; Short, 2007, 2011, 2013), feeding this back into undergraduate and postgraduate mental health nurse educational curricula.

The poem immediately below is constructed as four sets of three verses, written in free verse form. Each set is followed by a haiku placed contained within two lines of asterisks. These conform to the 5, 7, 5 syllable structure characteristic of this poetic genre and function to punctuate the poem with summaries of its developing themes. In co-developing and constructing the poem, Nigel wrote the twelve free verses and Alec the haikus. The poem overall is based on Nigel's experiences as an in-patient in an acute mental health unit in London over 15 years ago. These were originally described by him in autoethnographic narrative form (Short, 2011), and by both of us later in dialogical narrative and autoethnographic research contexts (Grant, 2013; Grant et al., 2015a).

In presenting the poem, we make no claims to be masters of the art of poetry. However, we do claim sufficient levels of knowledge about poetry and its construction principles, and more advanced expertise and authority in all the topics and their contexts alluded to in the poem.

\section{Mind yourself}

There is a bin man working in this town.

In the darkness, he plays with people's minds.

My awareness grabbed, I must attend to

his thoughts. They drop in unannounced and sparks fly. 
His dialogues, percolate through to me.

He penetrates my mind. Like a canyon,

deep and wide, he sets about his cruel task.

My tinder is crisp and vulnerable.

I play Arab songs to distract me. But his

dark scary intrusions defeat me again.

His rough barnacles scrape my soft underbelly.

I must find the escape button and press.

They live on both sides

of an imaginary wall,

with nowhere to climb.

Where is he now? The rude one? The sad one?

Does this petulant man care about us?

The lot he left behind?

I abhor his bitter, twisted, mischievous and unwanted

exhaustive moaning. 
Peace and quiet give me the comfort I need.

I can hear Big Ben chiming over the Thames.

Life was innocent then. Hand knitted jumpers, second hand books, with curled up yellow pages.

Towards the river: London Eye in view.

Standing with silent anticipation.

Standing with silent expectation.

I wandered, amused, now and again moved.

The time of London

is the space of London,

etched in our madness.

There, on the stage, the King of Africa, screaming.

His unflinching persistent war stories, with

plenty of mud and blood in his oblong cell.

His black legs and ribs are smashed and broken.

There they stand, upright, proud and keen above town.

London dirt dripping down their faces, just like me. 
I am invited to tour battlefields.

I've been tunnelling for days. I'm tired.

The sad Galia melons changes shape.

Bananas begin to spread and shed their

skins. Innocent Spanish oranges, turning mouldy,

neglected in their burial bowl.

Leaves dry and fruit rot

in a certain London where

we strayed, brittle-sweet.

Staring across the river, with silent

anticipation. With silent expectation,

I stood, I wondered, I was intrigued, and

now and again moved, again.

There at the base of the column,

The dark tableau sculpture

captures the vile, monstrous inhumanity of warfare. 
Me. Poignant, unsettling, troubling sleep.

The awaited May morning wakes up slowly.

Echoes of my previous darkness begins

to disappear over tall chrome buildings.

Shopkeepers, like me, preparing for a brand new day.

Leaving old London,

pressing it into the past,

we glimpse our future.

\section{Our explanation and analysis of the poem}

Nigel: In January 2000 I was admitted to an inpatient psychiatric unit in London. I stayed there, voluntarily, for several months, spending most of my time alone, concealing my disturbing interior dialogues. I made some rudimentary field notes on scraps of paper, ripped from magazines, of some of my experiences. The busy ward had many chaotic, noisy and unsettling moments. In response, I chose a self-imposed confinement in my quiet side room for long periods. 
The characters in the poem, the 'bin man' and 'King of Africa', are metaphors for, respectively, one particular member of the nursing staff and a Nigerian man I got to know. He was experiencing troubling and distressing beliefs about himself and others.

Join me on one excursion. I am walking towards the brutal architecture of the National Theatre on the south bank of the river. The sky is the same colour as the concrete. I am sandwiched in grey. I am making my way over Waterloo Bridge, down Victoria Embankment, and up Northumberland Avenue towards Trafalgar Square and St. Martin's Place. I can now see Charing Cross Road. I am going into an electronics shop. Picture me buying a silver Sony Walkman, some earplugs and some batteries. I am now walking to Tower Records in Piccadilly. I approach the counter and am asking for a CD by Amina Alaoui. I am putting the batteries into the Walkman. I am listening to her as I continue walking back to the hospital, anonymously. I am eating Falafels stuffed into warm pitta bread.

Most of the above experiences are alluded to in the poem, Including the fact that I was eventually discharged and returned to my home town. The dark shadows lifted and gradually a liberating light began to shine.

Alec: London is alluded to in several sense in the poem. It is a space where people are separated according to the relative power of the groups they belong to. In this sense, more specifically, 'London' is a chronotope. After Bakhtin, this term refers to space-time configurations that divide people into groups (Holquist, 2002). Although they may share the 
same geographical space, different people and groups always locate themselves in different space-times according to the particular meanings and significance events and experiences have for them. With regard to mental health practices, this is an important point, as a specific geographical space will mean myriad different things to the nurses and patients who are located within it (Grant et al., 2015a).

Though our dialogue over the years, we have come to regard 'London' as simultaneously a place of decay and, as conveyed in the last lines of the poem, a place of hope and renewal. It is ironic that we both had previous senior roles in the Institute of Psychiatry - the selfproclaimed 'centre of excellence' for mental health treatment and research in the UK, in the late-1990s. For several years, Nigel was a Tutor and Course Leader of 'Psychosocial Interventions for In-patient Mental Health Nursing Staff' while Alec's role was that of External examiner for the Thorn psychosocial interventions programme. In light of our 'survivor' status and our previous professional relationships with London as the epicentre of assumed excellence, 'London' has also grown in our collaboratively developing awareness as an extended metaphor, or allegory, which is emblematic of madness through time.

This is apparent in our poem, and in the work of authors we admire that implicitly and explicitly influences it. The words in the first haiku, 'both sides of an imaginary wall', roughly correspond with the 'Mind forged manacles' metaphor that William Blake used in his poem, 'London'. In our own poem these words refer to the fact that the divide, or wall, between Nigel and his fellow patients and the nurses, including the 'Bin Man', is an imaginary one. It is imaginary because it is based on an increasingly contested and discredited view of extreme human misery - the stuff of life that could potentially befall 
anyone - as 'mental illness' (Grant, 2015; Smith and Grant, 2016). Finally, the penultimate line in the poem, 'pressing it into the past' is borrowed from a novel by Will Self. In The Book of Dave, Self (2006) uses this phrase to refer to the fact that London constantly rebuilds and remakes itself in spite of periods of decay and destruction. This symbolises Nigel's own recovery journey, conveyed in our poem.

\section{Emerging benefits for nurse education}

On the basis of the above, we believe that poetry as hybrid pedagogy provides a clearly articulated and coherent platform for nurse educators. Its adoption as a curricular resource will enable them to trouble, challenge and revise long-held epistemological assumptions delimiting the range and scope of the undergraduate mental health nursing curriculum, its content and how it could be delivered. These developments would necessarily both unsettle and balance normative assumptions and practices informing knowledge and knowledge presentation in mental health nurse education. They would also encourage more mental health nurse educators to be open to using their own experiences of extreme psychological distress in this, and other related and creative ways.

As we argued earlier, such a development would also fit with the currently emerging Health Humanities paradigm in healthcare education internationally (Crawford et al., 2015). In this context, and in line with existing practice at the University of Brighton, poetry as hybrid pedagogy would sit well in 'Arts in Health' modules in undergraduate nurse education. 
Building on previous work in this general area, cited above, and on the basis of our own experiences, scholarship and pedagogic practices, we believe that these developments will reduce binarying, 'them' and 'us', and 'othering' assumptions in several ways. Specifically, they are likely to: help students attain a more advanced level of empathic attunement with service users (Jack, 2015); contribute to dismantling curricular and professional cultural barriers to perception (Rolfe, 2012); and further enhance both professional artistry (Chan 2014) and emotional intelligence (Jack, 2015) in mental health nursing practice.

The use of poetry as hybrid pedagogy will thus also advance paradigmatic and epistemological pluralism. This is essential in balancing biomedical with lived experience- based ways of knowing that relate to a more explicitly health humanities paradigm position. In the face of a co-evolving psychosocial paradigm that challenges institutional assumptions and practices, such disruption of the dominance of traditional forms of knowledge is arguably now a moral necessity in mental health nursing scholarship and practice (Grant, 2015; Smith and Grant, 2016).

Moreover, at a theoretical level, the use of poetry as hybrid pedagogy can assist nurses to become more narratively competent (Corbally and Grant, 2016), in helping them develop empathic imagination. In a related way, in terms of the relationships between mental health nurses and service users, the poetry as hybrid pedagogy approach can also go some way to addressing what Frank (2015, p3) describes as the problem of 'failure of dialogical recognition'. This phrase refers to nurses constructing knowledge of service users in ways almost exclusively informed by institutional practice assumptions (Grant, 2015; Smith and Grant, 2016). 
As Frank describes, we have found in our own work that this relates to and reinforces a divide between nurses and users. This divide is caused by the former group imposing often unwanted service-driven narratives on the latter (Frank, 2015; Grant, 2015; Smith and Grant, 2016). This in turn can result in users regarding nurses as lacking in empathy and understanding of their needs and wished-for directions of their lives (Grant et al., 2015a).

However, in spite of the benefits described above, it should be borne in mind that, to paraphrase the contemporary poet, Simon Armitage (2011), poetry is, by definition, often written as a form of oppositional dissent. We identify with this observation, and with Armitage's further assertion that it is often written by members of the 'awkward squad' who have a narrative axe to grind against the mainstream, which they are always reluctant to be part of (Armitage, 2011). Because of this, poetry as hybrid pedagogy is more likely to be appreciated by those mental health nurse students and academics who are attracted to it as a critical epistemological resource. In this regard, our argument may appeal most to the already epistemologically-converted.

\section{References:}

Armitage, S., 2011. Simon Armitage: 'poetry is a form of dissent' - video interview http://www.theguardian.com/books/video/2011/nov/07/simon-armitage-poetry-videointerview [accessed $10^{\text {th }}$ February, 2016].

Bakhtin, M., 1984. Rabelais and his world. Trans Iswolsky, H. Indiana University press, 
Bloomingdale, Indiana.

Cobley, P., 2014. Narrative. $2^{\text {nd }}$ edition. Routledge, London and New York.

Chan, Z.C.Y. 2014. Exploration of artistry in nursing teaching activities. Nurse Educ. Today. 34, 924-928.

Coleman, D., Willis, D.S, 2015. Reflective writing: The student nurse's perspective on reflective writing and poetry writing. Nurse Educ. Today. 35, 906-911.

Corbally, M., Grant, A., 2016. Narrative competence: a neglected area in undergraduate curricula. Nurse Educ. Today. 36, 7-9.

Crawford, P., Brown, B., Baker, C., Tischler, V., Abrams, B. 2015. Health Humanities. Palgrave Macmillan, Basingstoke.

Curtis, K., 2013. $21^{\text {st }}$ Century challenges faced by nursing faculty in educating for compassionate practice: Embodied interpretation of phenomenological data. Nurse Educ. Today. 33, 746-750.

Frank AW. 2015. From sick role to narrative subject: An analytic memoir. Health. Health (London). 2016 Jan: 20(1): 9-21. Doi: 10.1177/1363459315615395.Epub 2015 Nov 18. 
Grant, A., 2010. Writing the reflexive self: an autoethnography of alcoholism and the impact of psychotherapy culture. Journal of Psychiatric and Mental Health Nursing. 17, 577-582.

Grant, A., 2013. Writing Teaching and Survival in Mental Health: A Discordant Quintet for One. In: Short, N. P., Turner, L., Grant, A. (Eds.), Contemporary British Autoethnography. Sense Publishers, Rotterdam.

Grant, A., 2015. Demedicalising misery: welcoming the human paradigm in mental health nurse education. Nurse Educ. Today. 35, e50-e53.

Grant, A., Leigh-Phippard, H., Short, N.P., 2015a. Re-storying narrative identity: a dialogical study of mental health recovery and survival. Journal of Psychiatric and Mental Health Nursing. 22, 278-286.

Grant, A., Zeeman, L., Aranda, K., 2015b., Queering the relationship between evidencebased mental health and psychiatric diagnosis: Some implications for international mental health nurse curricular development. Nurse Educ. Today. 35, e18-e20.

Holquist, M., 2002., Dialogism. Second edition. Routledge, London and New York.

Jack, K. 2015. The use of poetry writing in nurse education: An evaluation. Nurse Educ. Today. 35, e7-e10. 
McKie, A., 2012., Using the arts and humanities to promote a liberal nursing education. Nurse Educ. Today. 32, 803-810.

Richardson, L., 1993., Poetics, Dramatics, and Transgressive Validity: The Case of the Skipped Line. The Sociological Quarterly. 34(4), 695-710.

Richardson, L., 2000., Writing: A method of inquiry. In: Denzin, N., Lincoln, Y. (Eds.), Handbook of Qualitative Research. $2^{\text {nd }}$ edition. SAGE Publications Ltd, London.

Rolfe, G., 2012., The marriage of heaven and hell. William Blake 1790. Nurse Educ. Today 32, 195-196.

Self, W., 2006., The Book of Dave: A Revelation of the Recent Past and the Distant Future. Penguin, London.

Short, N. 2007., Feeling Misunderstood. In: Hardcastle, M., Kennard, D., Grandison, S., Fagin, L. (Eds.), Experiences of Mental Health In-Patient Care. Routledge, Hove.

Short, N. P., 2011., Freeze Frame: Reflections on Being in Hospital. In: Grant, A., Biley, F., Walker, H. (Eds.), Our Encounters with Madness. PCCS books, Ross-on-Wye.

Short, N. P., 2013., An Englishman Abroad: An Autoethnographic Tale. In: Short, N. P., Turner, L., Grant, A. (Eds.), Contemporary British Autoethnography. Sense Publishers, Rotterdam. 
Short, N. P., Turner, L., Grant, A. (Eds.). 2013. Contemporary British Autoethnography. Sense Publishers, Rotterdam.

Smith, S., Grant, A., 2016. The corporate construction of psychosis and the rise of the psychosocial paradigm: Emerging implications for mental health nurse education. Nurse Educ. Today. (39) 22-25. 